\title{
A Dandy-Walker Variant Prenatally Diagnosed Using Ultrasound on One of the Fetuses of a Twin Pregnancy Obtained through In Vitro Fertilization
}

\author{
Dinu-Florin Albu', Cristina-Crenguta Albu², Stefan-Dimitrie Albu ${ }^{3}$ \\ ${ }^{1}$ Dr. Dinu-Florin Albu, MD, PhD, Ass. Professor, Obstetrics \& Gynecology and Medical Genetics, Expert in Maternal-Fetal \\ Ultrasound and Maternal-Fetal Medicine, ${ }^{2}$ Dr. Cristina-Crenguta Albu, MD, PhD, Ass. Professor, Ophthalmology and \\ Medical Genetics, ${ }^{3}$ Stefan-Dimitrie Albu, Medical Student, All are affiliated with University of Medicine and Pharmacy \\ Carol Davila, Bucharest, Romania and Alco San Clinic, Maternal-Fetal Medicine Dept., Bucharest, Romania
}

Corresponding author: Dr. Cristina-Crenguta Albu, E-mail: stevealbu@yahoo.com

Address for Correspondence: 27A, Catedrei Street, $1^{\text {st }}$ District, 014162, Bucharest, Romania

\begin{abstract}
We present the case of a patient aged 42 years, who was sterile of undiagnosed nature and who resorted to IVF, as a last resort to get pregnant. Following this procedure, a twin pregnancy resulted.

Ultrasound investigation, of the "second opinion" type performed using a Voluson E8 ultrasound 4D module highlighted: twin pregnancy 34.1 weeks old in evolution; A female fetus without visible malformations on the ultrasound, estimated weight of 2,300 g; B female fetus with borderline ventriculomegalia and vermis hypoplasia with Dandy-Walker cyst appearance, plus a rare malformation association, hypotelorism. Estimated fetal weight is 2,500 g.

It is the first case described in the specialized literature of a version of Dandy-Walker syndrome prenatally diagnosed on one of the fetuses of a twin pregnancy, resulting from in vitro fertilization. The probable etiology of the malformation is genetic, hence the need for careful supervision of all high-risk pregnancies and the need of genetic counseling and consultation, with the final aim of limiting the appearance of affected newborns.
\end{abstract}

Keywords: Dandy-Walker Syndrome, Ultrasound, Twin Pregnancy, IVF, Vermis, Prenatal Diagnosis

\section{Introduction}

The Dandy-Walker syndrome is a brain malformation that occurs in the 4th week of the pregnancy [1]. This involves the total or partial absence of a portion of the cerebellum [vermis], which is associated with the important dilatation of the fourth ventricle and hydrocephalus [2].

It is a rare condition, with a frequency of $1: 25,000$ to 30,000 newborns [3], with a higher incidence in females [4].

The disease may have multiple causes: genetical $[5,6]$, chromosomal [7], toxic or infectious. Dandy-Walker syndrome may associate other brain malformations [8], in $70 \%$ of the cases, for example agenesis of corpus callosum and malformations of other organs, in $20-30 \%$

Manuscript received: $24^{\text {th }}$ Nov 2014

Reviewed: $6^{\text {th }}$ Dec 2014

Author Corrected; $17^{\text {th }}$ Dec 2014

Accepted for Publication: $28^{\text {th }}$ Dec 2014 of cases, such as heart, kidney, facial, digital or vertebral defects [9].

The diagnosis of the Dandy-Walker syndrome may be established since intrauterine life, especially during fetal morphology examination in the second trimester of pregnancy, when there may be total or partial agenesis of the cerebellar vermis, as an isolated malformation or associated with other malformations [10].

The vermis agenesis can be viewed using ultrasound as a cystic image [11] that connects the third and fourth ventricles [12].

The Dandy - Walker Syndrome may have three versions: 1. The classical Dandy-Walker malformation (enlargement of the posterior fossa, cerebellar vermis agenesis, tall/ high tentoriu, hydrocephalus); 


\section{Case Report}

2. Dandy-Walker variant [variable hypoplasia of cerebellar vermis, with or without enlargement of the posterior fossa), and

3. Megacisterna magna (enlarged cisterna magna, keeping the integrity of the cerebellar vermis and of the fourth ventricle).

The aim of this paper is to present the first case described in the specialized literature of the Dandy-Walker syndrome Version diagnosed in one of the fetuses of a dizygotic twin pregnancy, pregnancy resulting from in vitro fertilization.

\section{Case Report}

The patient E.L., aged 42 years, comes to the clinic in her 34 week pregnancy for an ultrasound specialist investigation of the "second opinion" type. From previous medical history we establish that the patient is known to have infertility, of an unspecified cause, she was subject to prolonged treatment but without getting any results. As a result, the couple decided to use IVF, as the last opportunity to achieve a pregnancy. We have to mention that it is a Caucasian couple and non consanguine.

Following in vitro fertilization, the current twin pregnancy was obtained (Figure 1).

The ultrasound examination performed using a Voluson E8 ultrasound, 4D module shows the following:

The A fetus (Figure 2) shows lower skull, head biparietal diameter: $84.4 \mathrm{~mm}$, occipito-frontal head diameter: 108.5 $\mathrm{mm}$ and head circumference: $304.4 \mathrm{~mm}$. The cerebellum has normal structure and configuration: $44.5 \mathrm{~mm}$. Cerebral hemispheres are symmetrical and have a normal compliance. Cisterna magna and Cavum septum pellucidum are also normal in size. The Sulcus lateralis cerebri is visible and the ventricular system shows normal size. The choroid plexus are homogeneous. Blood flow in the middle cerebral artery shows the following values: PSV: $63 \mathrm{~cm} / \mathrm{s}$, EDV: $7.83 \mathrm{~cm} / \mathrm{s}$, S/D: 8.05, PI: 2.23, RI: 0.88 (normal range).

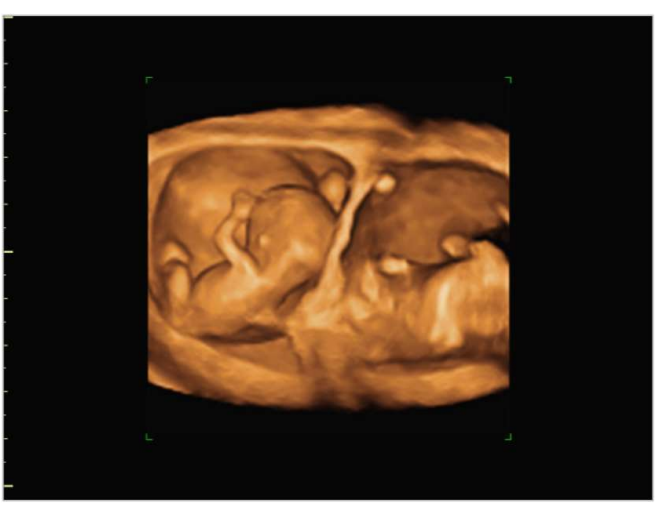

Figure 1 - Twins pregnancy, 19 weeks

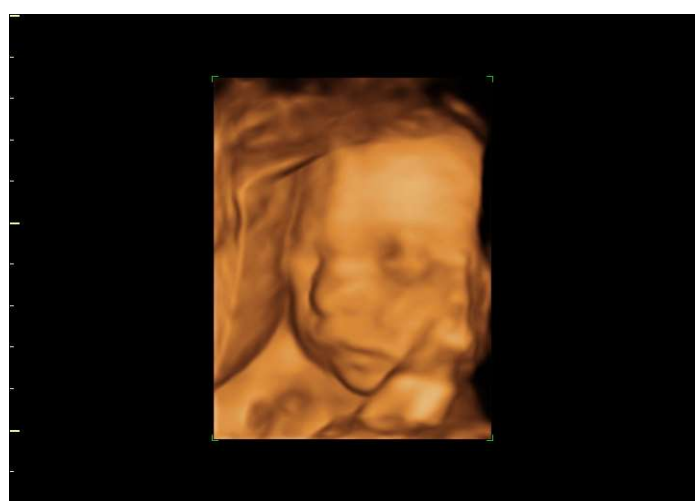

Figure 2 - Twin A, normal

The neck has a normal configuration, as well as the spine, without visible DTN over $0.5 \mathrm{~cm}$. The thorax has normal form and structure, anterior-posterior diameter: $87 \mathrm{~mm}$ and transverse diameter: $82.5 \mathrm{~mm}$. The heart is tetra cameral, rhythmic activity, BCF: 129 beats/min. The large vessels at the base of the heart show an apparently normal laying out.

The abdomen is normally configured with anterior-posterior diameter: $99 \mathrm{~mm}$, transverse diameter: $89.2 \mathrm{~mm}$ and abdominal circumference: $295.7 \mathrm{~mm}$. Fundic pelvis, Female. Upper and lower limbs are tri-segmental, with normal configuration with humerus: $59.3 \mathrm{~mm}$ and femur: $68 \mathrm{~mm}$.

The umbilical cord presented is tri-vascular. Umbilical artery blood flow has the following values: PSV: $69.85 \mathrm{~cm} / \mathrm{s}$, EDV: $26.56 \mathrm{~cm} / \mathrm{s}, \mathrm{S} / \mathrm{D}: 2.63$, PI: 0.91, RI: 0.62 (normal range). The amniotic fluid volume is in normal quantity and presents circulation.

The placenta is located in the right corner, presents homogeneous structure, degree of maturation II and thickness: $39 \mathrm{~mm}$ at the insertion of the umbilical cord. 
Fetus B (Figure 3) presents the lower skull, brain biparietal diameter: $90.8 \mathrm{~mm}$, occipito-frontal brain diameter: $113.8 \mathrm{~mm}$ and head circumference: $321 \mathrm{~mm}$. Cerebellum, $48 \mathrm{~mm}$, with abnormal structure and configuration. Vermis hypoplasia: 23 $\mathrm{mm}$ (Dandy-Walker cyst aspect) (Figure 4). Cerebral hemispheres are symmetrical and have normal configuration. TCED: $33 \mathrm{~mm}$. Cavum septum pellucidum and Sulcus lateralis cerebri - visible. The ventricular system presents posterior corner: $12.9 \mathrm{~mm}$ (0.39 ICp), homogeneous choroid plexus. Blood flow in the middle cerebral artery: PSV: $64.36 \mathrm{~cm} \mathrm{s,} \mathrm{EDV:} 8.85$ $\mathrm{cm} / \mathrm{s}, \mathrm{S} / \mathrm{D}$ 7.27, PI: 2.3, RI: 0.86 (normal range).

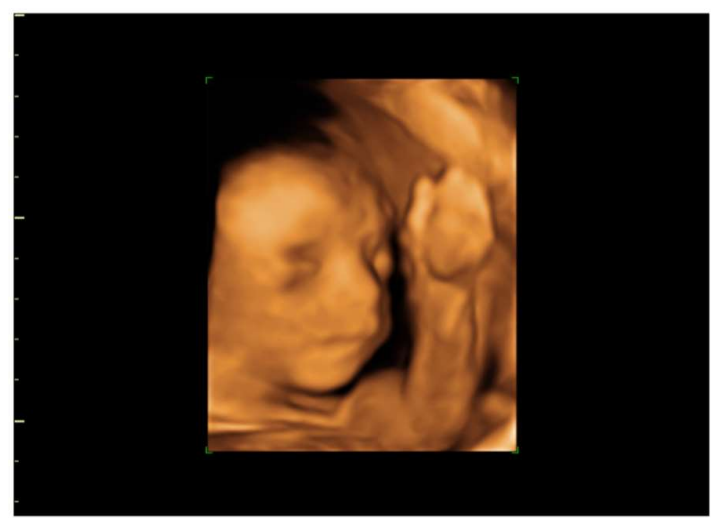

Figure 3 - Twin B, affected

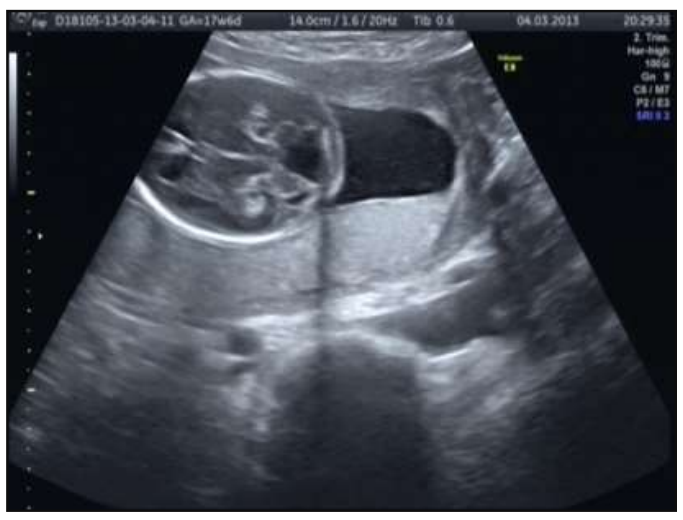

Figure 4 - Dandy-Walker cyst aspect, Vermis hypoplasia
Anterior fossa: external interorbital distance: $52.5 \mathrm{~mm}$ (hypotelorism), internal: $21 \mathrm{~mm}$. The neck has a normal configuration, as well as the spine without visible DTN over $0.5 \mathrm{~cm}$. The thorax presents normal shape and structure, with anterior-posterior diameter: $76.4 \mathrm{~mm}$ and transverse diameter: $85 \mathrm{~mm}$. The heart is tetra cameral, rhythmic activity, BCF: 143 beats/min.

The large vessels at the base of the heart show apparently normal configuration. Aperture visible. The abdomen has a normal configuration with anterior-posterior diameter: $92.4 \mathrm{~mm}$, transverse diameter: $100.6 \mathrm{~mm}$ and abdominal circumference: $303.3 \mathrm{~mm}$. Fundic pelvis background female.

Upper and lower limbs are tri-segmental, of normal configuration, with humerus: $58.4 \mathrm{~mm}$ and femur: 65.6 $\mathrm{mm}$.

The umbilical cord is tri-vascular. Umbilical artery blood flow presents the following values: PSV: $55.08 \mathrm{~cm} / \mathrm{s}$, EDV: $17.75 \mathrm{~cm} / \mathrm{s}, \mathrm{S} / \mathrm{D}: 3.1$, PI: 1.07, RI: 0.68 (normal range).

The velocimetry of uterine arteries records the following data: the right uterine artery blood flow: L/R: 2, PI: 0.76, RI: 0.50 (normal range), left uterine artery blood flow: S/D: 1.96, PI: 0.74, RI: 0.49 (normal range).

International Journal of Medical Research and Review
Amniotic fluid volume is in normal quantity and presents circulation. The placenta located on the bottom and rear wall to the left, presents homogeneous structure, maturation degree I-II and thickness: $33 \mathrm{~mm}$ at the insertion of the umbilical cord.

On the basis of ultrasound final diagnosis includes twin pregnancy of 34.1 weeks in evolution. $2^{\text {nd }}$ fetus diagnosed with borderline ventriculomegalia, hypoplasic vermis (Dandy-Walker cyst aspect), hypotelorism. Estimated weight: A fetus: 2,300 g; B fetus: 2,500 g.

\section{Discussion}

Since the ultrasound examination performed at 34 weeks of pregnancy indicates: ventricular system with posterior corner: $12.9 \mathrm{~mm}$ (0.39 ICp) and hypoplasic vermix: 23 $\mathrm{mm}$ (Dandy-Walker cyst aspect), the result is that the B fetus presents the Dandy Walker version/ variant (cerebellar vermis variable hypoplasia, with or without enlargement of the posterior fossa) and not the classical Dandy-Walker malformation [13] (enlargement of the posterior fossa, cerebellar vermis agenesis, high tentorium, hydrocephalus).

Regarding cause of the malformation, given the maternal physiological personal history (age over 40 years) and the maternal pathological personal history (sterility) its genetic etiology can be incriminated for two reasons: on 
the one hand, the sterility can be the the genetical cause, and on the other hand, older age of the mother may favor the occurrence of non-disjunction of chromosome and therefore numerical chromosomal abnormalities in fetuses [14].

In terms of elucidating the etiology, we must mention that no cytogenetic tests were performed either on the couple before IVF or to the two fetuses in the necessary prenatal diagnosis, considering the risk pregnancy [15].

The chorionic villus biopsy performed 10 to 12 weeks of pregnancy or at least, the amniocentesis performed later, in pregnancy weeks 14-16 would have been indicated [7]. By performing fetal karyotypes it would have been able to determine if the fetus $\mathrm{B}$ shows a chromosomal abnormality $[9,17]$.

\section{The Prognosis}

The prognosis $[9,18]$ in cases of Dandy-Walker syndrome is not good especially if the existence of a chromosomal abnormality is suspected.

\section{The peculiarities of the case}

1. Twin pregnancy, obtained after in vitro fertilization, two female fetuses, one normal (fetus A) and the other affected (the fetus B).

2. Fetus B, malformed, presents the Dandy-Walker syndrome Variant and not the classical Dandy-Walker malformation.

3. The Dandy-Walker variant, presented by B fetus is associated with hypotelorism, a very rare association.

4. Prenatal diagnosis was established later, at 34 weeks of pregnancy.

\section{Conclusions}

From the above-mentioned information, the following conclusions are drawn:

1. The necessity of accurate, complete and multidisciplinary investigation of all couples before performing the in vitro fertilization procedure.

2. The need for careful supervision of all high-risk pregnancies, in specialized centers.

3. The need for prenatal genetic consultation and genetic counseling aimed ultimately at limiting the incidence of malformed newborns.

\section{References}

1. Entezami M, Albig M, Knoll U et-al. Ultrasound Diagnosis of Fetal Anomalies. Thieme Medical Publishers, (2003) ISBN:1588902129.
2. Albu D., Albu C., Dumitrescu M, Severin E. Prenatal diagnosis of Dandy-Walker malformation: case report. European Human Genetics Conference, Austria, Vienna, 2009

3. Ecker JL, Shipp TD, Bromley B et-al. The sonographic diagnosis of Dandy-Walker and Dandy-Walker variant: associated findings and outcomes. Prenat. Diagn. 2000;20 (4):328-32

4. Albu D., Deva D., Albu C., Severin E. Prenatal ultrasound detection of a Dandy-Walker malformation: Case report. International Congress on Prevention of Congenital Diseases. Journal of Inherited Metabolic Disease, Volume 34, Supplement 1, 116, DOI: $10.1007 / \mathrm{s} 10545-011-9312-\mathrm{x}$

5. Barkovich AJ, Millen KJ, Dobyns WB. A developmental and genetic classification for midbrainhindbrain malformations. Brain. 2009;132 (Pt): 3199230 .

6. Estroff JA, Scott MR, Benacerraf BR. Dandy-Walker variant: prenatal sonographic features and clinical outcome. Radiology. 1992 Dec;185(3):755-8.

7. Oncescu A, Albu D., Albu C. The utility of the echographic exam in detection of cromosomal abnormalities and other pluri malformative syndromes associated with Dandy-Walker syndrome: review of 15 cases in 2012. Ultrasound in Obstetrics \& Gynecology, John Wiley \& Sons, Ltd., ISSN 0960-7692, 2013; 42, Suppl. 1: 113-179, 149.

8. Muncean M.G., Cioata I.T., Huditeanu A., Motoc A., Munteanu I. Dandy-Walker Syndrome Variety in the Context of a Polimalformative Syndrome. The Limits of Conventional Ultrasound Examination. Timisoara, Medical Jurnal, nr. 3-4, 2008.

9. Oncescu A, Albu D., Albu C. The utility of the echographic exam in detection of cromosomal abnormalities and other pluri malformative syndromes associated with Dandy-Walker syndrome: review of 15 cases in 2012. Ultrasound in Obstetrics \& Gynecology, John Wiley \& Sons, Ltd., ISSN 0960-7692, 2013; 42, Suppl. 1: 113-179, 149.

10. Ulm B, Ulm MR, Deutinger J, Bernaschek G. Isolated Dandy-Walker malformation: prenatal diagnosis in two consecutive pregnancies. Am J Perinatol. 1999;16(2):61-3. 
Case Report

11. Harper T, Fordham LA, Wolfe HM. The fetal dandy walker complex: associated anomalies, perinatal outcome and postnatal imaging. Fetal Diagn Ther. 2007;22(4):277-81.

12. Has R, Ermiş H, Yüksel A, Ibrahimoğlu L, Yildirim A, Sezer HD, Başaran S. Dandy-Walker malformation: a review of 78 cases diagnosed by prenatal sonography. Fetal Diagn Ther. 2004 Jul-Aug;19(4):342-7. Review.

13. Klein O, Pierre-Kahn A, Boddaert N, Parisot D, Brunelle F. Dandy-Walker malformation: prenatal diagnosis and prognosis. Childs Nerv Syst. 2003 Aug;19(7-8):484-9. Epub 2003 Jul 16.

14. Imataka G, Yamanouchi H, Arisaka O. DandyWalker syndrome and chromosomal abnormalities. Congenit Anom (Kyoto). 2007 Dec;47(4):113-8. Review.

15. Sasaki-Adams D, Elbabaa SK, Jewells V, Carter L, Campbell JW, Ritter AM. The Dandy-Walker variant: a case series of 24 pediatric patients and evaluation of associated anomalies, incidence of hydrocephalus, and developmental outcomes. J Neurosurg Pediatr. 2008 Sep;2(3):194-9. doi: 10.3171/PED/2008/2/9/194.

16. Koul RL, Chacko A, Leven HO. Dandy-Walker syndrome in association with neurofibromatosis in monozygotic twins. Saudi Medical Journal 2000; Vol. 21 (4): 390-392.

17. Kumbak, Banu; Bor, Meltem; Bahçeci, Mustafa. Dandy-Walker Variant in A Fetus of an ICSI Twin Gestation: A Case Report. Balkan Medical Journal; Jun2011, Vol. 28 Issue 2, p219.

18. Spennato P, Mirone G, Nastro A, Buonocore MC, Ruggiero C, Trischitta V, Aliberti F, Cinalli G. Hydrocephalus in Dandy-Walker malformation. Childs Nerv Syst. $2011 \quad$ Oct;27(10):1665-81. doi: 10.1007/s00381-011-1544-4. Epub 2011 Sep 17. Review.

\section{How to cite this article?}

Dinu-Florin Albu, Cristina-Crenguta Albu, Stefan-Dimitrie Albu. A Dandy-Walker Variant Prenatally Diagnosed Using Ultrasound on One of the Fetuses of a Twin Pregnancy Obtained through In Vitro Fertilization. Int J Med Res Rev 2015;3(1):127-131. doi:10.17511/ijmrr.2015.i1.22 